\title{
Improving the Energy Efficiency of Cyclone Dust Collectors for Wood Product Factories
}

\author{
Philippe Beaulac ${ }^{1}$, Mohamad Issa ${ }^{1,2}$, Adrian Ilinca' ${ }^{1}$, Richard Lepage ${ }^{1}$, Fahed Martini ${ }^{1}$ \\ ${ }^{1}$ Department of Mathematics, Informatics and Engineering, Université du Québec à Rimouski, Rimouski, Canada \\ ${ }^{2}$ Department of Pure and Applied Sciences, Institut Maritime du Québec à Rimouski, Rimouski, Canada \\ Email: Philippe.Beaulac@uqar.ca, Missa@imq.qc.ca
}

How to cite this paper: Beaulac, P., Issa, M., Ilinca, A., Lepage, R. and Martini, F. (2021) Improving the Energy Efficiency of Cyclone Dust Collectors for Wood Product Factories. Open Journal of Energy Efficiency, 10, 97-119.

https://doi.org/10.4236/ojee.2021.103007

Received: August 2, 2021

Accepted: September 26, 2021

Published: September 29, 2021

Copyright (c) 2021 by author(s) and Scientific Research Publishing Inc. This work is licensed under the Creative Commons Attribution International License (CC BY 4.0).

http://creativecommons.org/licenses/by/4.0/

\section{Open Access}

\begin{abstract}
Dust collection systems represent a significant portion of a wood product manufacturer's total electricity use. The system fan works against the static pressure of the entire system-the blast gates, the ductwork, and the upstream or downstream cyclone and/or baghouse. A poor system design (e.g., sharp elbows or undersized ductwork) increases the total amount of static pressure in the system, the fan's performance curve shifts, increasing the total brake horsepower required by the fan (up to the maximum point on the curve). Additionally, system designers may oversize a dust collection system to ensure adequate dust capture and transport, either to accommodate system expansion or simply to be conservative. Since theoretical fan energy use increases with its velocity cubed, this can be an expensive safety net. This paper presents a comprehensive literature review about industrial cyclone dust collectors energy saving in relation to management, technologies, and policies. Energy-saving technologies like high-efficiency motors (HEMs), variable-speed drives (VSDs), leak detection, and pressure drop reduction have all been examined. Based on energy saving technologies results, it has been found that in the industrial sectors, a sizeable amount of electric energy, and utility bill can be saved using these technologies. Finally, various energy-saving policies were reviewed.
\end{abstract}

\section{Keywords}

Cyclone Dust Collector, Energy Saving, Energy Management, Variable Speed Drive (VSD), Highly Efficient Motors, Leak Prevention, Regulations/Standards

\section{Introduction}

Energy is a basic required resource in industrial facilities all over the world for a 
variety of functions. For countries with rapid economic growth, a large amount of energy is required. As a result, energy is a critical component of economic competitiveness and job creation.

Many efforts need to be exerted to bring the global energy resource to a better management level, and all efforts should not be excluded. This paper presents an aspect of energy efficiency on a typical high energy consuming industrial system, such as dust collectors and their related sub-systems. The aim of this paper is to improve the energy efficiency of the cyclone dust collectors for wood product factory.

The second section of this article presents a literature review on the subject of energy consumption emphasized on wood transformation factories. It also presents the actual situation and its impact on the global market.

The third section presents an overview of energy management strategies for dust collecting systems.

The fourth section presents energy saving solutions which pertains to mechanical aspects of dust collecting systems, and the fifth section presents solutions for their electrical aspects.

The sixth section presents incentives for energy savings in industrial application of dust collector systems, according to policies, regulations and standards.

The seventh section presents practical recommendations for energy savings.

The eighth section presents a conclusion for this article.

\section{Literature Review and Problem Statement}

Global population and energy demands, on the other hand, are growing in lockstep. The world community must address this challenge to avoid future energy resource shortages. From 2010 to 2030, global marketed energy consumption is expected to rise by $33 \%$. As illustrated in Figure 1, total world energy use increased from $82,919 \mathrm{ZW}$ in 1980 to $116,614 \mathrm{ZW}$ in 2000 and is anticipated to reach 198,654 ZW in 2030 [1].

In the above context, there is certainly a need for more research and diagnostics

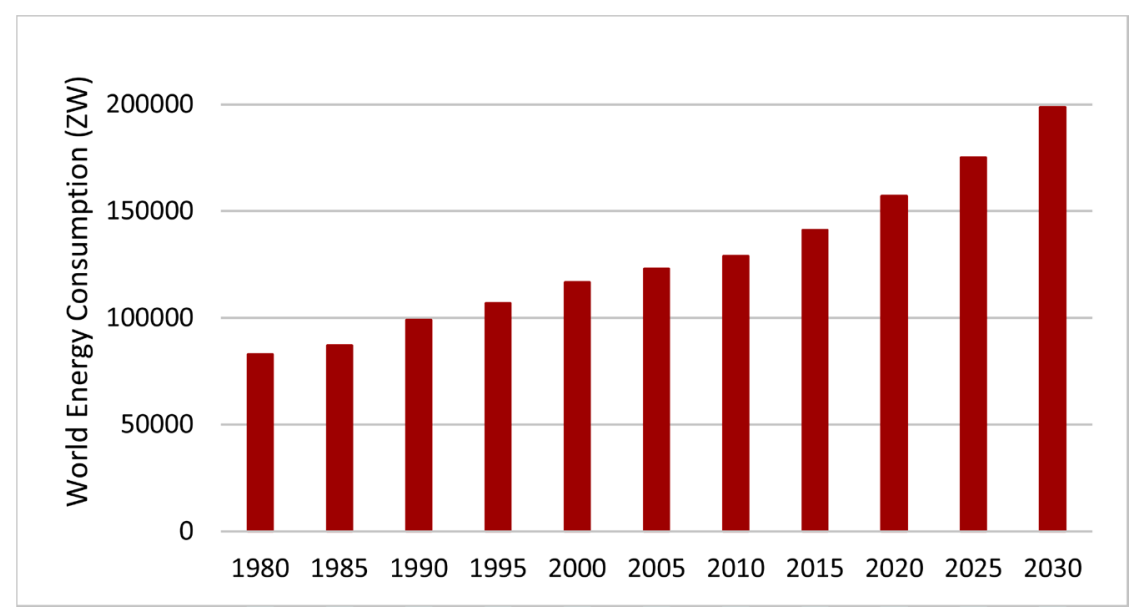

Figure 1. World marketed energy consumption from 1980 to 2030 (ZW) [1]. 
in the different industrial sectors, especially in those where very little efforts have been concentrated in the past. Wood products and furniture manufacturing are part of those industries where more research efforts are required in terms of energy saving. For a typical woodworking shop, the largest demand of electricity is usually concentrated in two applications: dust collection and compressed air. Dust collection alone can represent up to $50 \%-60 \%$ of the total electrical consumption of a woodworking facility.

Despite their industrial operations exceeding 140 years, the world is constantly refining the design of cyclone dust collectors capable of effectively capturing fine dust at a low cost. As a result, one of the most significant environmental challenges is to improve the energy efficiency of cyclones [2]. Many studies have been carried out over the world to increase cyclone energy efficiency, and new better cyclone designs have been proposed.

In [3], a cyclone with an extra chamber for collecting tangential dust in the structure's conical section was presented. This, according to the authors, would improve the effectiveness of catching tiny dust particles (less than $6 \mu \mathrm{m}$ ). The findings of numerical modeling revealed that when the cyclone's hydraulic resistance is increased by $8 \%$, particles with a diameter of $3 \mu \mathrm{m}$ are caught $50 \%$ more efficiently. The drawback of the cited work is the increased cyclone resistance and the lack of tests under industrial conditions.

It is shown in [4] [5] that the suction of gas from the vortex duster bunker with oncoming swirling streams can reduce dust removal by more than 3 times and increase dust cleaning efficiency. The disadvantages of such modernization include the need for additional equipment, a lower diameter duster and an additional fan to suck gases from the bunker.

The results of tests of a standard helix cyclone "CN-15u-300" and a patented cyclone with the reverse cone "COK-200-300" that allows the depth of the exhaust pipe dive to be controlled are reported in Study [6]. It is shown that the resistance of "COK-200-300" is 2-2.2 times less than that of the conventional cyclone "CN-15u-300", and the efficiency of dust capture up to $5 \mu \mathrm{m}$ increases by about $5 \%-20 \%$. However, the drawbacks include the fact that the reported work used a cyclone design, which is incapable of efficiently separating the two-phase flow from particles smaller than $5 \mu \mathrm{m}$ in diameter.

Installing various types of stream straighteners in the exhaust pipe is the most common method of lowering cyclone wind-dynamic resistance. Thus, the authors of work [7] [8] investigated the cleaning indicators of a vortex cyclone apparatus with a diameter of $0.4 \mathrm{~m}$ fitted in the exhaust pipe, as well as several stream straighteners following it, all under the same industrial settings. Dolomite dust was used with an average median particle diameter of $18 \mu \mathrm{m}$ and a density of $2100 \mathrm{~kg} / \mathrm{m}^{3}$. It is shown that the stream straighteners (a conical blade, screw-blade, ring diffuser, in the form of a drop on the end), installed both in the exhaust pipe and after it, lead to a deterioration in the efficiency of cleaning the vortex duster. Only for the helix type stream straightener did the dust removal 
drop by 1.5 times on average, while the hydraulic resistance decreased by $11 \%$. The stated paper has one weakness: the results were only achieved for the tested design of the vortex cyclone equipment.

The authors of work [9] proposes a cycle filter combining a cyclone and a sleeve filter for gas purification at temperatures up to $130^{\circ} \mathrm{C}$ and a high beginning dust concentration in a single complex gas treatment system. This combination of cleaning procedures in a cyclone at significantly different airspeeds (at an average speed of up to $5 \mathrm{~m} / \mathrm{s}$ in a cyclone, and at a speed approximately one order of magnitude less in the sleeve filter) is considered as inadequate.

A multi-channel cyclone reported in [7] is of interest, the distinctive feature of which is the possibility to change the ratio of air dust mixture as it passes through the peripheral (return-incremental) and transit (moving to a new channel) streams. The highest value of purification efficiency in a three-tier sixchannel cyclone at a flow rate of $16 \mathrm{~m} / \mathrm{s}$ for dust particles less than $20 \mu \mathrm{m}$ (wood ash) was $92.8 \%$ and $95.1 \%$ for dust particles up to $50 \mu \mathrm{m}$ (granite dust). The disadvantage is the need to replace the existing cyclone with a newer model.

A multi-channel cyclone made of unalloyed material with an airflow consumption of $40,000 \mathrm{~m}^{3} / \mathrm{h}$ was examined in [10] when capturing lignin with a dispersity of $3 \mu \mathrm{m}$, the humidity of at least $95 \%$ at elevated temperatures $\left(50^{\circ} \mathrm{C}\right.$ $75^{\circ} \mathrm{C}$ ). Despite the high degree of dust purification of lignin, the internal "stuffing" of the cyclone was destroyed by temperature and humidity. The disadvantage is the need to fabricate cyclones from expensive materials.

Work [11] shows that the new swirling element in the separator design, compared to the traditional element of the vortex dust collector, contributes to an increase in overall efficiency. Thus, the purification increased by $2 \%-3 \%$ and the hydraulic resistance decreased by $30 \%$. The drawback is the lack of data on dust dispersal and the need to manufacture new equipment when replacing low-efficiency cyclones.

In [10], a method for increasing the energy efficiency of a baking cyclone heat recovery unit (6.25 $\mathrm{m}$ in diameter) of a rotary kiln in cement production, in which the exhaust pipe is eccentrically displaced relative to the cyclone axis, was considered. The parameters of the cleaned gases and dust were as follows: gas temperature $800^{\circ} \mathrm{C}$, dust density $2500 \mathrm{~kg} / \mathrm{m}^{3}$, gas speed in the inlet branch pipe $17 \mathrm{~m} / \mathrm{s}$. It is shown that when the magnitude of the exhaust pipe axis shifts relative to the axis of the cyclone by $100-200 \mathrm{~mm}(1.5 \%-3 \%$ of the diameter of the cyclone), the removal of dust from the cyclone decreased by 2 times.

The hydraulic resistance of the cyclone decreased by $5.4 \%$, and the energy efficiency of the cyclone increased by about 2.1 times. The drawback of this modernization is the lack of information about the dispersibility of the captured dust, as well as the possibility of its implementation only in the manufacture of a cyclone.

A method for increasing the efficiency of cyclones by reducing the removal of dust (a diameter of $4.5 \mu \mathrm{m}$ ) from the cyclone by 5 or more times, depending on 
the dispersibility of dust, is proposed in [12]. This outcome is accomplished by using various turbulence generators at the jet section to improve the degree of dust particulate treatment in cyclones. This modernization method has the advantage of being able to be implemented in cyclones used in numerous industries without having to replace them with new, more efficient, but also more expensive dust-trapping equipment. The drawback of such modernization is a certain increase in energy costs to overcome the hydraulic resistance of cyclones.

Thus, based on our analysis of existing methods of modernization of cyclone dust collectors, it is very useful to further develop new technologies to improve the energy efficiency of inefficient cyclones without replacing them with new ones. As a result, there has been a substantial increase in the number of scientific studies around the world focused at improving the energy efficiency of cyclone dust collectors since the beginning of the twenty-first century.

The most recent literature on industrial energy management, policies, and energy savings measures has been assembled in the form of $\mathrm{MS}$ and $\mathrm{PhD}$ theses, journal articles, conference proceedings, web resources, reports, books, and handbooks. Savings related to management have been examined, including energy audits, training programs, and housekeeping, as well as certain global energy management strategies. Energy-saving technologies like high-efficiency motors (HEMs), variable-speed drives (VSDs), economizers, leak avoidance, and pressure drop reduction have all been examined. Based on energy saving technologies results, it has been found that in the industrial sectors, a sizeable amount of electric energy, emissions and utility bill can be saved using these technologies.

\section{Energy Management}

The approach of satisfying energy demand when and where it is required is known as energy management. The objectives are to minimize energy cost/waste without affecting production and quality and minimize environmental effects. This can be accomplished by changing and optimizing energy utilizing systems and procedures to reduce energy requirements per unit of output while maintaining or lowering total costs of production from these systems [13]. As a result of growing energy prices and concerns about the world's energy resources being depleted, energy management became one of the key functions of industrial management in the 1970s. In today's sectors, energy management has taken on a far larger role. On a regular basis, the company's top management engages in the planning of various energy management programs. Many companies' annual reports should include specifics about their energy saving operations and their accomplishments in energy conservation programs [14]. To be effective, energy management programs should include four main sections: 1) Analysis of historical data; 2) Energy audit and accounting; 3) Engineering analysis and investments proposals based on feasibility studies; 4) Personnel training and information.

An energy management system implemented on a dust collector is composed 
of three things: a small control system, a Variable Frequency Drive (VFD) and automatic blast gates. As individual production applications are energized, the collector adapts its fan speed via a VFD control in order to provide adequate flow (cubic feet per minute, CFM) as needed. Each machine has a programmed minimum CFM requirement. The control system ensures the collector is always operating while machines are in function, as well as maintains the necessary CFM and velocity in the ducts. The benefits of doing this can be surprising. A slight reduction in RPM on the fan's motor equates to significant drop in energy usage. Slowing down the fan's motor as little as $20 \%$ reduces the power usage by $50 \%[15]$.

\section{Dust Collection Energy Saving-Mechanical Aspect}

\subsection{Hoods}

Dust collecting hoods can be built for one of two ventilation methods: collection or containment. It is vital to correctly select the appropriate approach for the application, as this will result in a wide range of hood designs. If a hood is used incorrectly, the system may experience excessive static pressure loss or require more air volume to accomplish the optimum dust collecting performance, both of which increase energy consumption [16]. The collection method must be designed to pull every fugitive dust particle produced by the process to the hood before it is released into the surroundings. As a result, the hood must be built to create higher capture velocities at a specific distance from the hood's face. On the other hand, in the containment methods, we aim at creating a negative pressure inside the process to prevent dust from fleeing the process equipment. This leads to the hood needing to be designed to have lower face velocities to minimize excess dust/product being pulled into the system while still creating negative pressure inside the equipment. Any leakage points in the equipment leak inward instead of puffing dust out due to the negative pressure. Large pyramidal/conical hoods are the most common hoods utilized in these settings, Figure 2.

When a collecting hood (slotted, for example) is used in a situation where a containment hood is necessary, excessively high face velocities are generated at the hood. Due to the orifice effect, these high velocities cause static pressure loss through the hood. In the worst-case situation, the hood is the controlling pickup points for the ventilation system, determining the overall pressure need. As a result of the excess static pressure generated in the hood, the overall system static pressure requirement is increased. This causes the fan's performance to move to the left on its fan curve and decrease the air flow of the system. To recover that loss in air volume the fan will be sped up, which increases the amp draw by the motor and results in the use of more energy to move the same amount of air that was originally intended.

Finally, when a containment hood (such as a big pyramidal) is used in an application where collection is necessary, the face velocities at the hood are lower. Because of the lower velocity, capture velocities are greatly reduced, and the dust 


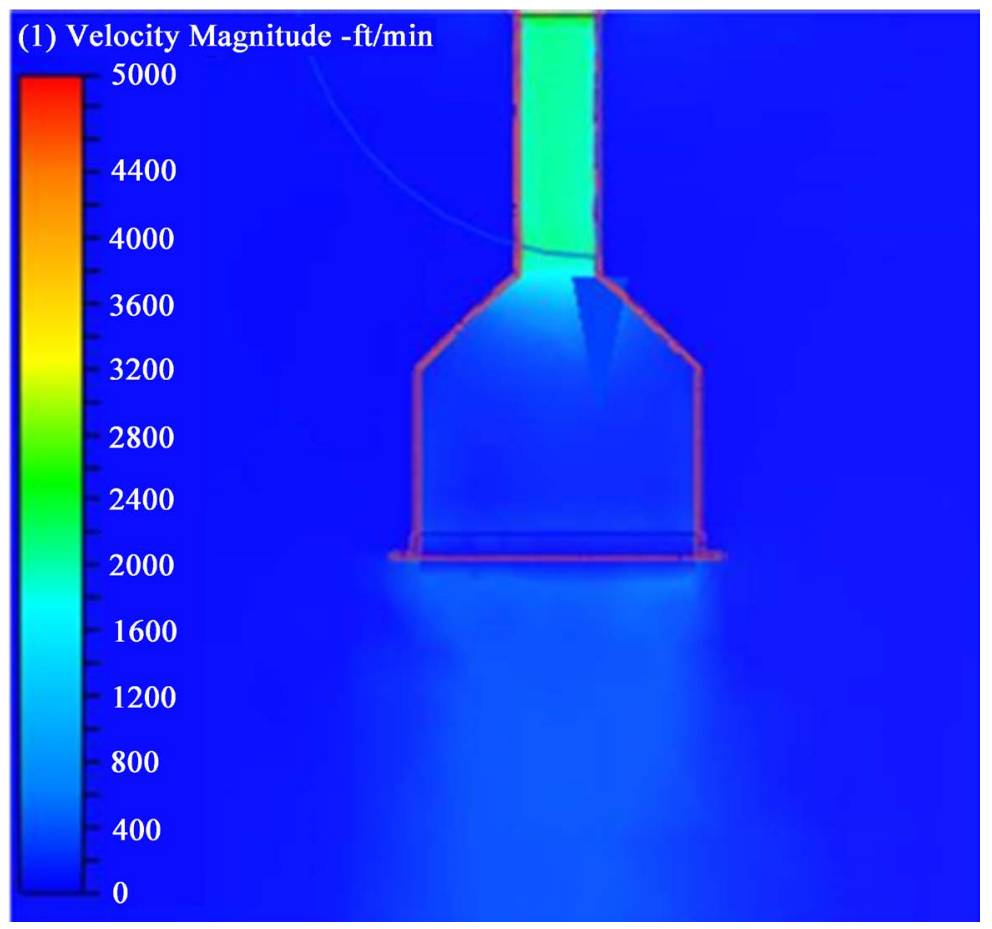

Figure 2. Slotted hood computational fluid dynamics (CFD).

is not caught. This also tends to increase the air flow to the hood by opening the blast gate/damper. With this increased air flow at this point there is a decrease in air flow to the remaining points in the system. To maintain the performance of the other pick-up points, a larger overall system air flow is required. When the fan is sped up to meet the greater total system air flow need, not only does the fan have to expend more energy to move more air, but the system's total pressure buildup also rises due to increasing frictional losses in the duct work.

\subsection{Duct Sizing}

When we size ductwork, we must obtain a balance to ensure that it will function properly. It must be small enough to keep dust flowing in the air stream throughout the system with adequate transport velocities while also keeping ducting material costs low. The other side of this balancing act is to make the duct as large as possible to reduce the system's velocity needs and static pressure, resulting in smaller fans and lower energy expenditures, Figure 3.

According to [17], dust will tend to settle to the bottom of ducts if the duct system is greater in diameter than required, causing dust buildup. As the buildup progresses, the cross-sectional area of the duct will be diminished. This decrease in cross section area results in the increase of air velocity in the duct and hence lower static pressure. If this fallout occurs anywhere along the governing branch's path of the total system, the static pressure will decrease as the velocity increases.

As the static pressure decreases, the fan parameters move to the right on its curve, which results in higher volumes. This can cause a cascading effect of dust 


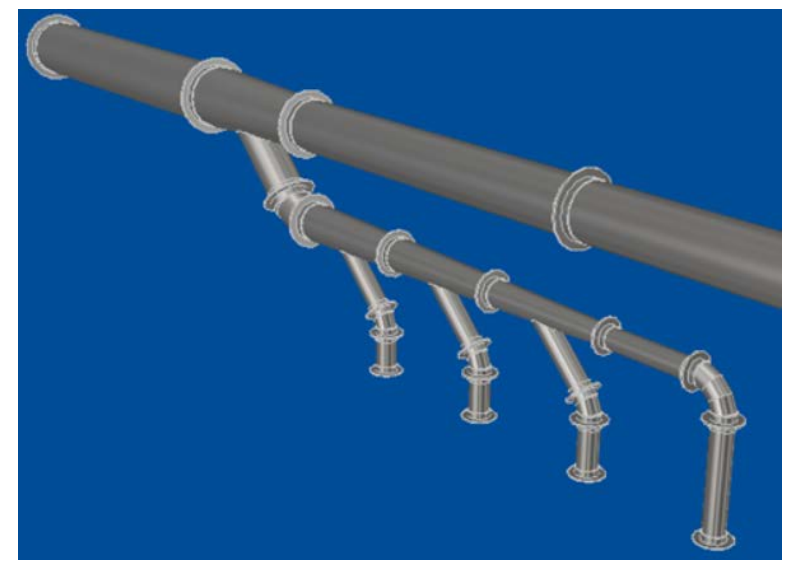

Figure 3. Illustration of 3D modeling of duct sizing.

build up resulting in lower pressure followed by higher volumes, increased velocities and to more buildup. Therefore, the cycle starts again that eventually leads to a completely plugged duct.

The velocity will create excessive pressure loss with a smaller diameter than required. If the fan's static pressure needs were calculated correctly with the increased pressure losses, the fan would pull the required air volume but consume more energy than a well-constructed system. If the fan's static pressure requirements were not calculated correctly, the higher than estimated pressure will cause the fan to move left on the curve and decrease the total air volume of the system. The decrease will require a speed change to the fan which causes more energy use.

\subsection{Layout}

The final item to consider for optimizing ductwork and reducing energy usage is the layout. Some characteristics of transport ducting are imposed by the actual layout of the production equipment of the factory, but the negative impacts and restrictions can be minimized or even eliminated by some simple strategies.

For instance, one of the most influential characteristic of a ducting network lies in the directing elbows. Excessive elbows for elevation changes are one of the most important things to consider in design (see Figure 4). Elbows cause excessive turbulence in the flow, hence greater loss of energy. Specialized pneumatic conveying elbows have been developed for minimizing losses due to turbulence: Hammertek [18] supplies these elbows to factories that rely on pneumatic conveying for material transport. Figure 5 shows 4 different types of Hammertek elbows. Figure 6 shows flow lines inside a Hammertek $90^{\circ}$ elbow.

Wang et al. [19] experimented and modelized a flow in an 8-inch-diameter duct with 1500 ACFM and a velocity of 4300 feet per minute. They configured their model as a straight duct with two elbows to impose a restriction in the flow and compare the pressure loss in three types of elbows (see Figure 7).

The static pressure loss in the configuration with two 90-degree elbows registered to 0.63 inches. When compared to two 45 -degree elbows, the static pressure 
(1) Velocity Magnitude - $\mathrm{ft} / \mathrm{min}$

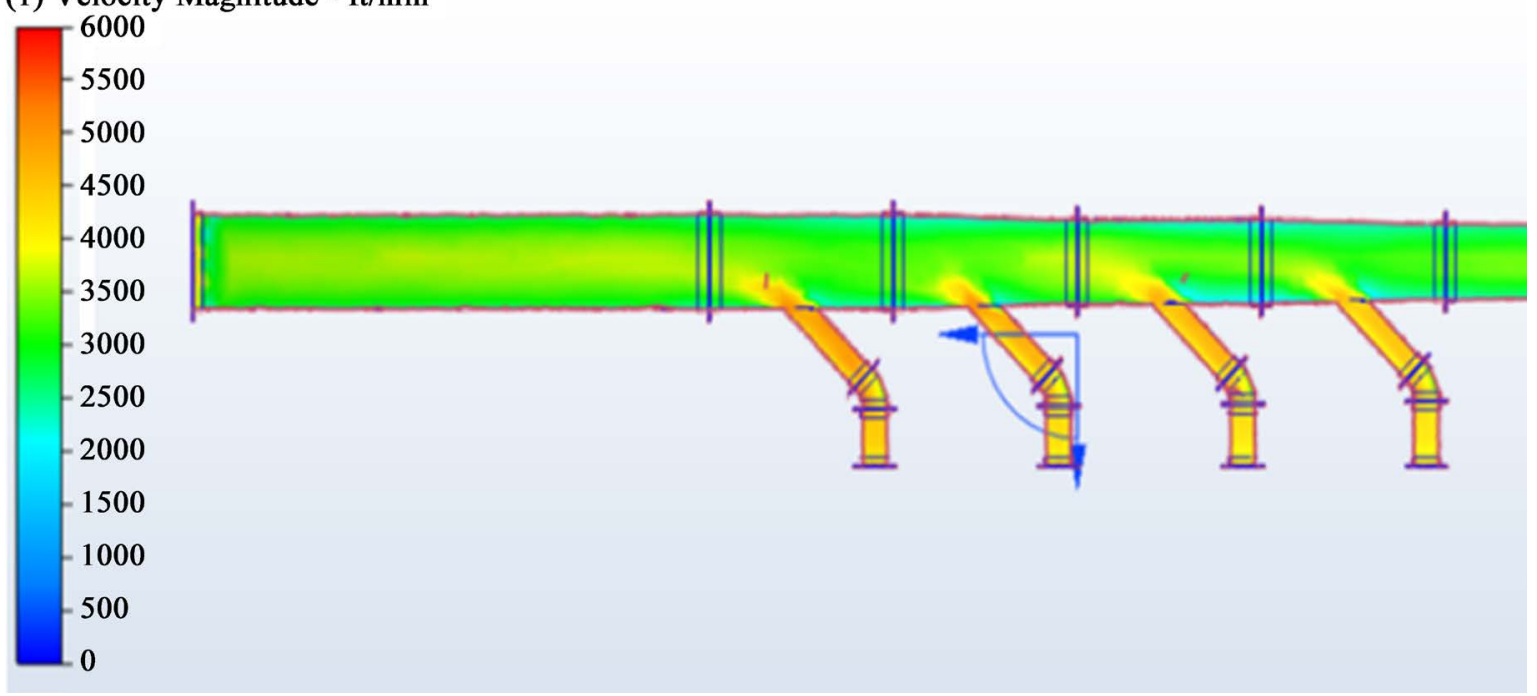

Figure 4. Trunk branch entries.

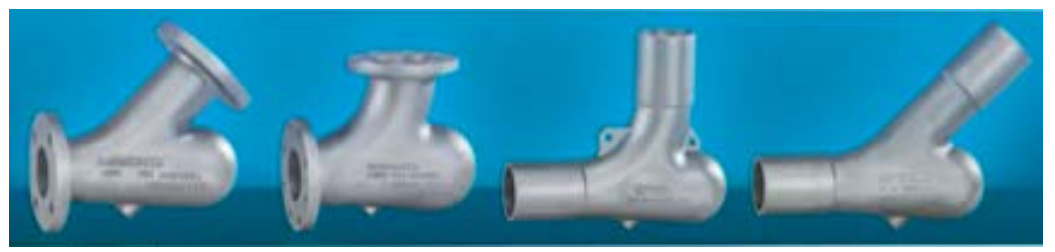

Figure 5. Hammertek elbows.

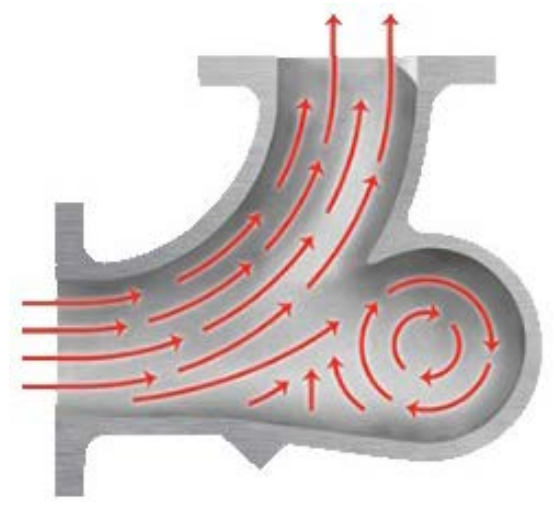

Figure 6. Optimized flow in Hammertek elbows.

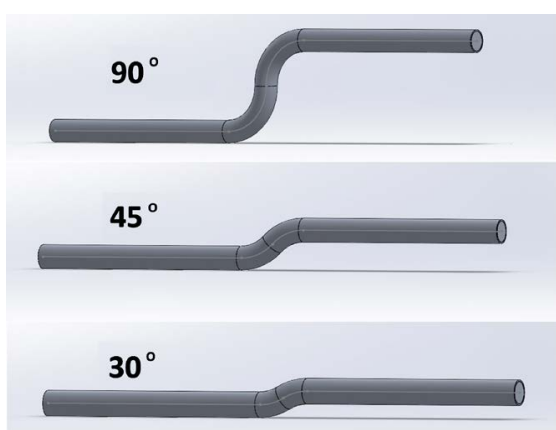

Figure 7. Models for pressure loss. 
loss is reduced to $0.31 \mathrm{in}$. wc, and even lower with two 30 -degree elbows at 0.21 in. wc.

On the governing branch path of the ductwork, that would result in $0.31 \mathrm{in}$. wc in the case of 45-degree elbows, or $0.21 \mathrm{in}$. wc in the case of 30-degree elbows, less pressure resistance for the fan and lower energy consumption. Another common place for improvement is when multiple pickup points are in close proximity to one another, and they are branched off the main duct that is a part of the governing branch path. With each branch entry there is a pressure loss from the turbulent mixing of the air streams so the more branch entries are installed in the governing branch path the higher the systems pressure resistance will be. The solution is to branch off once from the main governing branch and make a new branch line that will not exceed the governing branch diameter and deal with the connection losses of only one instead of four junctions with the governing branch.

\section{Dust Collection Energy Saving-Electrical Aspect}

Application of electrical technologies has tremendous potential to reduce industrial energy issues. The following are a few of them applied for dust collection energy savings.

\subsection{Variable Speed Drive}

A variable speed drive is an electronic power converter that produces a multiphase, variable frequency output that may be used to control and modify the speed, torque, and mechanical power output of a typical AC induction motor. If used in a variety of industrial applications, this mechanism can save a lot of energy [20]. AC drives can be described by different terms. Adjustable frequency drives (AFD), variable speed drives (VSD), variable frequency drive (VFD) and inverters all are employed, but have the same meaning. VSD's have been used to provide significant savings in several applications around the world such as pump velocities, motor speed control, blower speeds, conveyor systems and other application that require variable speed with variable torque [21] [22].

\subsubsection{Using a Variable Speed Drive to Reduce a Dust Collector Energy Usage}

Dust collectors use electricity for the duration of its operation, with most of it being consumed by the fan's motor. The energy required by the fan's motor can be reduced by using a VFD. The volume of air (or CFM) that the fan moves through the system is directly proportional to the amount of energy consumed. Dust collectors are mechanisms that can be adjusted. Depending on how dust-filled the filter cartridges are, their resistance to airflow (pressure drop) fluctuates over time. Without any intervention, in the early stages of the filters' life when the static pressure across them is low, the fan will move more air than needed [23]. This consumes unnecessary energy and causes air to hit the filters at a high velocity, which reduces filter life. The VFD, equipped with an airflow 
or static pressure sensor, will automatically sense changes in airflow and pressure drop, and will adjust the fan speed to return the system to optimal airflow. Operators achieve significant electrical savings over the long term because the amount of energy needed to operate the fan's motor varies with speed. The drive reduces fan speed to get the desired airflow when the filters are new. When the filters become clogged with dust, the drive increases the fan speed to maintain a steady airflow. In terms of maintaining the required airflow while consuming the least amount of electricity, electronic control is far more efficient than human intervention. Adjusting the frequency of the incoming power is an effective way to change the fan's motor speed since their relationship is directly proportional. For example, a VFD can change a motor that runs at $3600 \mathrm{RPM}$ at $60 \mathrm{~Hz}$ to run at $1800 \mathrm{RPM}$ at $30 \mathrm{~Hz}$. The fan draws only the amount of power required for the specific fan speed. For example, a fan that runs $25 \%$ slower would use $42 \%$ of the power that would be required for full speed. The same fan running $50 \%$ slower would use $12 \%$ of the full speed power. Figure 8 illustrates the multiple

\section{Speed Control (VFD)}

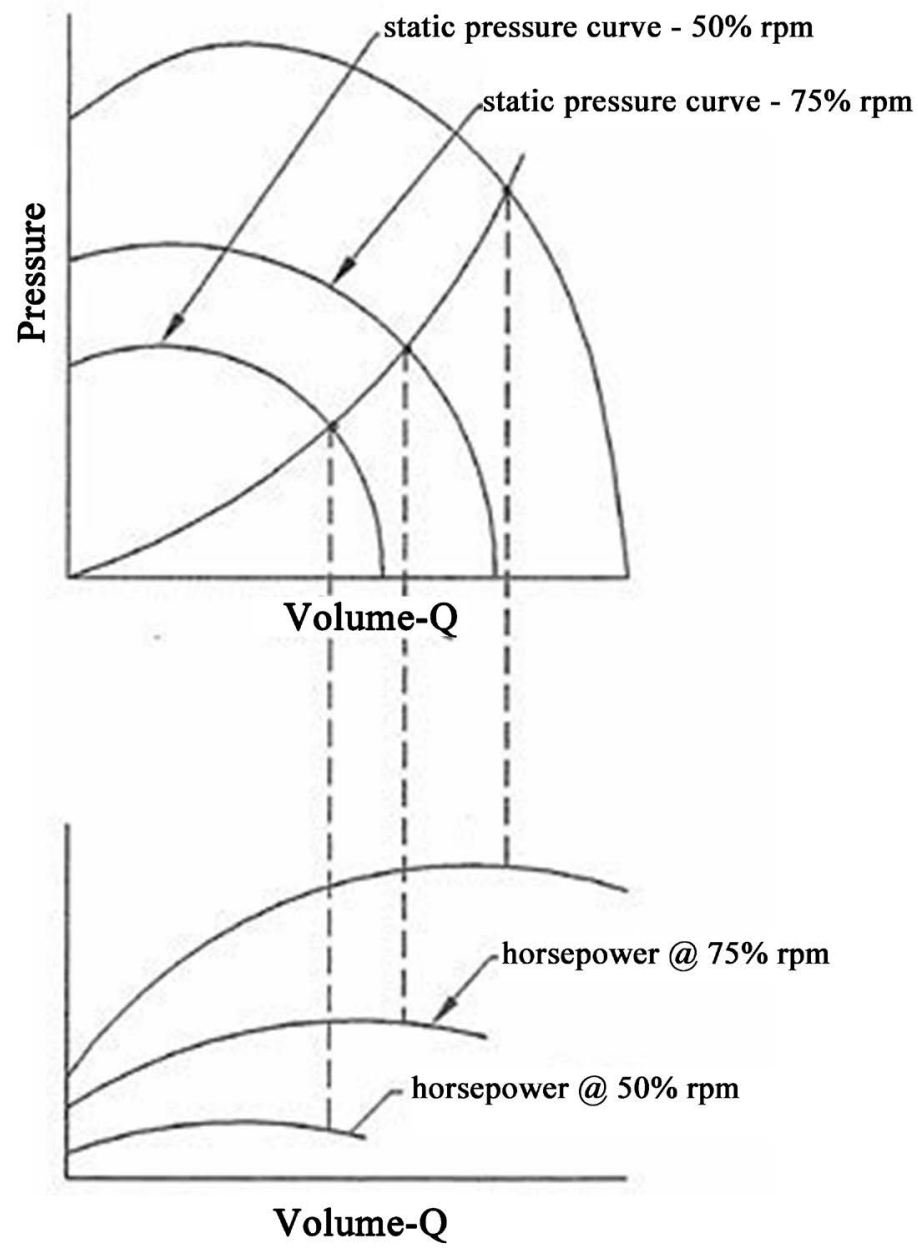

Figure 8. Energy relationship of a variable speed fan by means of mechanically controlling the static pressure of the system via an outlet damper. 
relationships that define the amount of energy being used at different speeds. VFD have been proven to save an average of $4 \mathrm{in}$. wc of static pressure over the life of the filters. With different applications, the additional capital cost reductions available by installing a VFD on a dust collection system would vary. However, the average return on investment is less than a year.

\subsubsection{Mathematical Formulations to Estimate Energy Savings Using VSD}

The following calculation can be used to calculate the annual energy consumption of electrical motors that do not use variable speed drives:

$$
A E C_{B A U}=M_{H p} \times 0.7456 \times N_{\text {motors }} \times O P H / \eta_{\text {motor }}
$$

where $A E C_{B A U}$ is the annual energy consumption without variable speed drive (kWh/year); $M_{H p}$ is the motor's power in horsepower; $N_{\text {motors }}$ represents the number of motors used; OPH represents the operating hours in year (h/year) and $\eta_{\text {motor }}$ is the efficiency of the motor.

Annual energy consumption when using variable speed drive depends on annual energy consumption without using VSD and speed reduction ratio. This can be calculated from the following equation:

$$
A E C_{N P}=A E C_{B A U} \times\left(1-S R_{\text {ratio }}\right)^{2}
$$

where $A E C_{N P}$ is the annual energy consumption with VSD (kWh/year) and $S R_{r a}$ tio is the speed reduction ratio.

The difference between yearly energy consumption without VSD and annual energy consumption with VSD is the annual energy savings when utilizing VSD. The annual energy savings are calculated as follows:

$$
A E S_{V S D}=A E C_{B A U}-A E C_{N P}
$$

Table 1 shows the potential energy savings associated with the speed reduction using a VSD for industrial motors [23].

\subsubsection{Mathematical Formulations to Estimate Cost Saving When Using a VSD}

The annual bill savings can be determined using VSD based on annual energy savings and energy unit price. The following is the formula for the cost reduction mentioned above:

$$
A B S_{V S D}=A E S_{V S D} \times U E P
$$

where $A E S_{V S D}$ is the annual energy saving when using VSD (kWh/year), and

Table 1. Potential saving of VSD when reducing the speed.

\begin{tabular}{cc}
\hline Average speed reduction (\%) & Potential energy saving (\%) \\
\hline 10 & 22 \\
20 & 44 \\
30 & 61 \\
40 & 73 \\
50 & 83 \\
\hline
\end{tabular}


$U E P$ is the unit energy price $(\$ / \mathrm{kWh})$.

Payback period is determined by the incremental cost of VSD divided by the annual bill saving of VSD in a particular year. Payback period can be expressed mathematically according to the following equation:

$$
P B P_{V S D}=I C_{V S D} / A B S_{V S D}
$$

where $I C_{V S D}$ is the incremental cost of VSD (\$), and $A B S_{V S D}$ is the annual bill saving of VSD (\$/year).

It is estimated that replacing conventional motors with adjustable speed motors in appropriate applications would result in saving $41 \%$ of the energy used in industrial motors. Power consumption drops far more than the drop in motor speed, so the savings can accumulate quickly. For example, a 10\% reduction in shaft speed results in a $27 \%$ decrease in power consumption [24].

\subsection{High Efficiency Motors (HEM)}

Electric motors consume most of the electricity in the industrial wood manufacturing sector. Wood cutting machines, fans, materials conveyors and air compressors all employ electric motors. However, there are four basic types of losses in a squirrel-cage induction motor:

- Stator and Rotor losses ( $\mathrm{I}^{2} \mathrm{R}$ losses in the stator and rotor windings).

- Core (magnetic) losses. This is the sum of the laminated stator and rotor core's hysteresis and eddy current losses.

- Friction and windage. This is the loss due to fans and the bearing friction.

- Stray losses. This is the sum of all motor losses that cannot be assigned to one of the other four types of losses. Electrical harmonics and stray currents in the motor are the main causes.

It is important to note that a normal motor is already a highly efficient device, with efficiency levels above $80 \%$ for most of the operating range and over $90 \%$ at full load. Motor manufacturers, on the other hand, have been able to boost efficiency even more with the following enhancements:

- Improved steel properties

- Thinner lamination

- Increase conductor volume

- Modified slot design

- Narrowing air gap

- Improved rotor insulation

In 2005, the European Committee of Manufacturers of Electrical Machines and Power Electronics (CEMEP) and the European Commission have devised motor efficiency classification labels EF1, EF2 and EF3 to make it much easier for purchasers to identify energy-efficient motors in the market with EF1 level as threshold. The motor manufacturers label their standard motors with efficiency logos [25] [26] [27].

Highly efficient motors offer many benefits for dust collector application. Some of these benefits include: 
- Less maintenance and longer lifetime due to lower temperature in windings and bearings

- Higher reliability due to lower losses, including:

1) Better tolerance to thermal stresses resulting from stalls or frequent starting

2) Increased ability to handle overload conditions

3) Better resistance to abnormal operating conditions, such as under and over voltage or phase unbalance

4) Higher tolerance to poorer voltage and current wave shapes.

\subsubsection{Mathematical Formulations to Estimate Energy Savings by HEM}

The following equations can be used to calculate annual energy savings (AES) when a standard electrical motor is replaced with a HEM:

$$
\begin{aligned}
A E C_{B A U}= & M_{H p} \times 0.7456 \times N_{\text {motors }} \times O P H / \eta_{\text {standard motor }} \\
A E C_{N P}= & M_{H p} \times 0.7456 \times N_{\text {motors }} \times O P H / \eta_{\text {ef motor }} \\
& A E C_{H E M}=A E C_{B A U}-A E C_{N P}
\end{aligned}
$$

Based on Equations (6)-(8), when installing HEM, the results of total annual energy saving in kWh are illustrated in Figure 9.

So there is tremendous potential of energy savings when a HEM is used in a dust collector. According to Figure 9, a 75 hp dust collector can save up to $28,000 \mathrm{kWh}$ per year at $100 \%$ load and up to 22,000 of $\mathrm{kWh}$ at $75 \%$ of load.

Considering the price of a $\mathrm{kWh}$ at 0.07 \$CA in Quebec, this represents a saving of $2000 \$$ when the motor is fully loaded.

\subsubsection{Cost-Benefit Results When Using a HEM}

Annual bill savings are related to annual energy savings and the unit price of energy while employing HEM. The following is the formula for the value strategy mentioned above:

$$
A B S_{H E M}=A E S_{H E M} \times U E P
$$

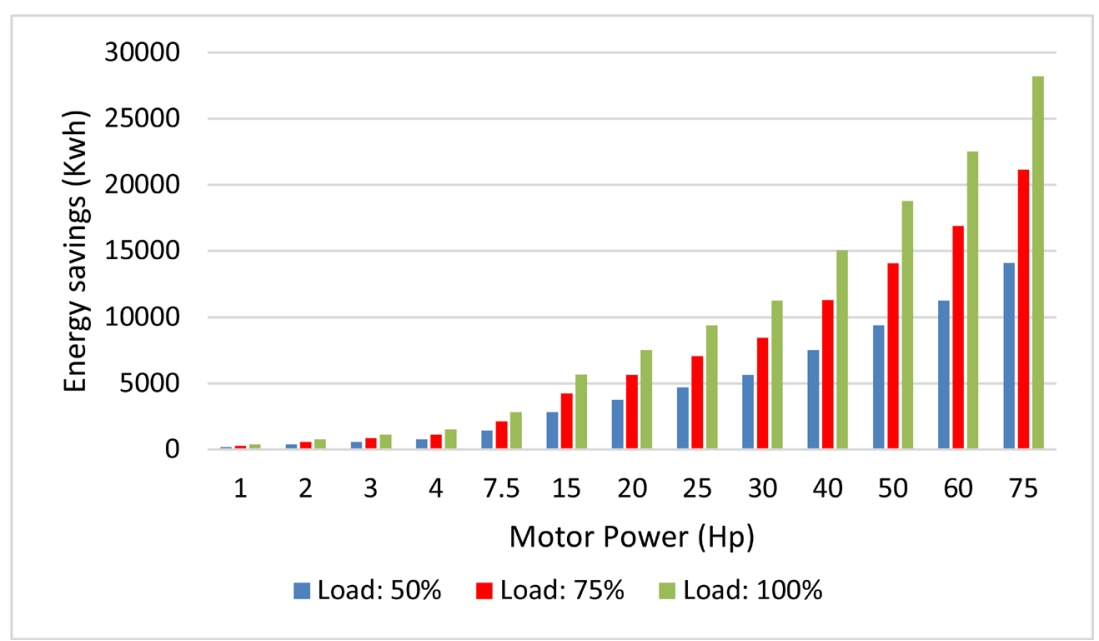

Figure 9. Energy savings $(\mathrm{kWh})$ for highly efficient dust collector motor applications [24]. 
The payback period is calculated by dividing the incremental cost of HEM by the annual bill savings of HEM each year. The following equation can be used to calculate the payback period:

$$
P B P_{H E M}=I C_{H E M} / A B S_{H E M}
$$

According to Saidur et al. [24], the findings of total annual bill savings and payback period are shown in Table 2 when HEM are installed in industrial motors and based on Equations (9) and (10).

\subsection{Energy Savings through Leak Prevention in Dust Collector}

Leaks in a dust collection system can waste the system's energy and cause material settlement and buildup (Figure 10), as well as degrade the dust collection system's performance. Leaks can occur at duct or pipeline couplings, diverters, elbows where holes have formed, blast gates, and in dust collector housings. The

Table 2. Bill savings and payback period for HEM.

\begin{tabular}{|c|c|c|c|c|c|c|c|}
\hline \multirow[b]{2}{*}{$\mathrm{Hp}$} & \multirow{2}{*}{$\begin{array}{c}\text { Incremental } \\
\text { cost }(\$ C A)\end{array}$} & \multicolumn{2}{|c|}{ Load (50\%) } & \multicolumn{2}{|c|}{ Load (75\%) } & \multicolumn{2}{|c|}{ Load (100\%) } \\
\hline & & $\begin{array}{l}\text { Bill savings } \\
\text { (\$CA) }\end{array}$ & $\begin{array}{c}\text { Payback } \\
\text { (year) }\end{array}$ & $\begin{array}{l}\text { Bill savings } \\
\text { (\$CA) }\end{array}$ & $\begin{array}{c}\text { Payback } \\
\text { (year) }\end{array}$ & $\begin{array}{l}\text { Bill savings } \\
\text { (\$CA) }\end{array}$ & $\begin{array}{c}\text { Payback } \\
\text { (year) }\end{array}$ \\
\hline 1 & 32.46 & 13.16 & 2.46 & 19.74 & 1.64 & 26.32 & 1.23 \\
\hline 2 & 38.12 & 26.32 & 1.45 & 39.41 & 0.96 & 52.57 & 0.73 \\
\hline 3 & 35.44 & 39.48 & 0.90 & 59.15 & 0.59 & 78.90 & 0.45 \\
\hline 4 & 74.75 & 52.64 & 1.42 & 78.89 & 0.94 & 105.21 & 0.71 \\
\hline 7,5 & 166.48 & 98.63 & 1.70 & 147.91 & 1.12 & 197.26 & 0.84 \\
\hline 15 & 296.32 & 197.68 & 1.50 & 296.52 & 1.00 & 394.94 & 0.75 \\
\hline 20 & 324.91 & 263 & 1.23 & 394.45 & 0.82 & 525.91 & 0.61 \\
\hline 25 & 451.78 & 328.65 & 1.37 & 492.94 & 0.92 & 657.30 & 0.69 \\
\hline 30 & 493.47 & 394 & 1.25 & 590.87 & 0.84 & 788.00 & 0.63 \\
\hline 40 & 592.64 & 526.12 & 1.12 & 789.18 & 0.75 & 1052.24 & 0.56 \\
\hline 50 & 623.32 & 656.6 & 0.94 & 984.83 & 0.63 & 1313.27 & 0.47 \\
\hline 60 & 786.82 & 788.5 & 1.00 & 1182.65 & 0.66 & 1576.82 & 0.50 \\
\hline 75 & 987.24 & 988.05 & 1.00 & 1481.90 & 0.66 & 1975.70 & 0.50 \\
\hline
\end{tabular}

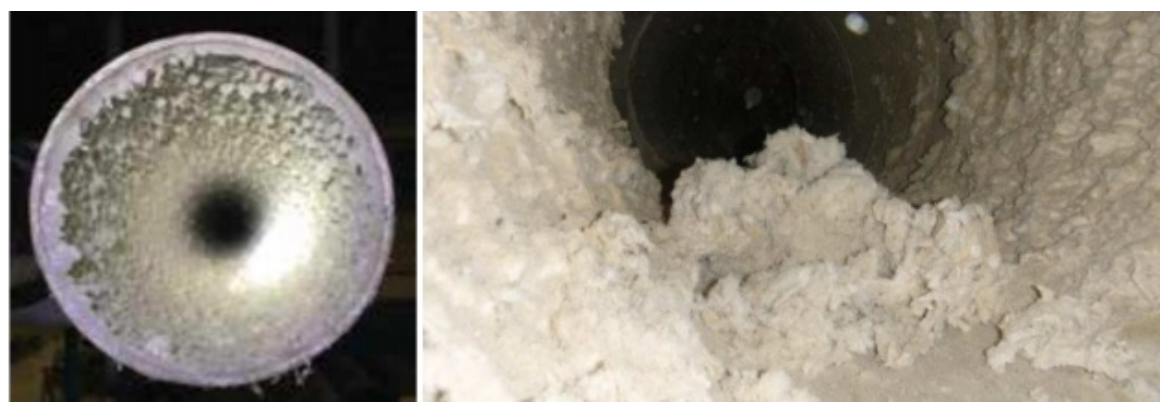

Figure 10. A significant buildup problem with resin pellets in a conveying line due to a leak. 
use of talcum powder, helium tracing, or non-combustible smoke around suspected leak spots can all be used to check for leaks [28].

The air alone moving through the system with the buildup exceed the system resistance design condition, thereby rendering dust collection impossible as solids are introduced in the system. The buildup problem was a result of temperature-induced softening of the resin, allowing the material to fuse to pipeline's interior. This creates an increase of friction and reduces the pipeline's diameter, which both significantly increase the system's resistance to air passage, solids transport and energy consumption. Power losses increase exponentially as the diameter of the hole increases as shown in Figure 11 [29] [30].

\section{Industrial Energy Saving by Policies}

Energy policy refers to how a specific institution (typically a government) has chosen to address challenges of energy development, such as energy production, delivery, and consumption. Legislation, international treaties, investment incentives, agreements, energy conservation guidelines, taxation, energy efficiency standards, and energy guide labels are all examples of energy policies [31]. Energy policies are used widely in the industrial sector to meet specific energy uses or energy efficiency targets. Industrial energy policies can be viewed as tools for developing long-term strategic plans, covering periods of 5 - 10 years, for increasing industrial energy efficiency and reducing greenhouse gas emissions. This strategy involves not only industrial facility engineers and management, but also the government, industry associations, financial institutions, and others. To promote energy efficiency in the industrial sector, countries around the world have implemented a variety of laws and programs. Some of these policies and programs include the following:

- Regulations/standards

- Fiscal policies

- Agreement/targets

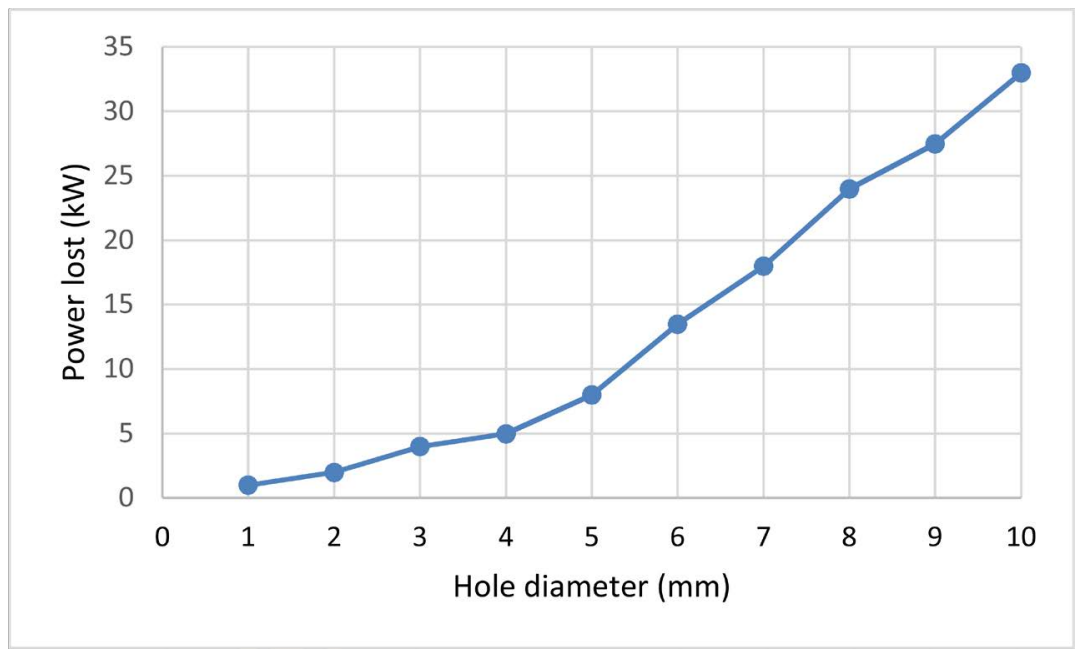

Figure 11. Dependence of power loss on hole diameter at $600 \mathrm{kPa}$ [29]. 


\subsection{Regulations/Standards}

Regulations and standards are policies that must be followed in order to improve energy efficiency. Typically, regulations and standards are applied to specific industrial equipments, such as motors, boilers, and so on. Furthermore, industrial establishments may be required to undertake energy audits, hire an energy manager, or implement an energy management system under laws. Example of regulations and standards in some countries are shown in Table 3 [31] [32] [33] [34].

\subsection{Fiscal Policies}

Imposition of taxes, tax refunds, investment tax credits, and the establishment of investment bank lending conditions are all examples of fiscal policies that promote energy efficiency. Taxation policies are a necessary tool for promoting energy efficiency adoption. Using tax refunds or investment tax credits, tax policies can also influence energy efficiency. Investment bank lending criteria can be established to give higher priority for funding projects that improve energy efficiency [35].

\subsection{Agreements/Targets}

In the industrial sector, agreements are frequently utilized to accomplish certain energy uses or efficiency targets. These agreements are characterized as "agreements between government and industry to facilitate voluntary acts with desirable social results, which are advocated by the government, to be conducted by the participants, based on the preferences of the participants. An agreement can be written in a variety of ways, but the most typical are those that are based on precise energy efficiency improvement targets and those that are based on energy consumption or carbon emission reduction commitments. Either an individual company or an industrial subsector, as represented by a party such as an industry association, can enter into such agreements. Some of these policies are tabulated in Table 4.

\subsection{Energy Policy in Canada}

The Canadian Industry Program for Energy Conservation is a wholly voluntary program in which each industrial sector sets collective targets. The sector task forces, as part of the program, identify energy efficiency opportunities, assess,

Table 3. Regulations and standards in some countries around the world.

\begin{tabular}{cc}
\hline Country & Industrial Policy \\
\hline Canada & Canada's Energy Efficiency Regulations \\
USA & U.S. Energy Policy Act Motor Efficiency standards \\
Brazil & Minimum Efficiency levels for high-efficiency motors \\
Italy and Japan & The Mandatory Energy Manager Programs \\
\hline
\end{tabular}


Table 4. Industrial sector policies in some countries around the world.

\begin{tabular}{ccc}
\hline Country & Industry policy & Reference \\
\hline Canada & Industry Program for Energy Conservation (CIPEC) & {$[36][37]$} \\
Denmark & Agreements on Industrial Energy Efficiency & {$[38][39]$} \\
Germany & Declaration of German Industry on Global Warming Prevention & {$[40]$} \\
U.K. & Climate change Levy, Efficiency Best Practice Program, & {$[42]$} \\
France & Make a Corporate Commitment & {$[43][44]$} \\
Sweden & Voluntary Agreements on CO CO Reductions $_{2}$ & {$[45]$} \\
China & China's National Climate Change Programme, Energy Conservation Law & {$[48]$} \\
\hline
\end{tabular}

and address the barriers to these opportunities, plans and implements strategies to realize the opportunities. The program includes annual measuring and reporting by industry participants. Benchmarking is conducted in which facilities are compared to the industry's average as well as to a "best practice" which is defined as the top quartile. Between 1973 and 1990, this program achieved cumulated energy savings of $26.1 \%$ per unit of production represented an ongoing reduction of 30.4\% in Canada's industrial emissions. Since 1990, this program has seen an average annual energy intensity improvement of $0.9 \%$. Also, since 1990, GDP from the CIPEC industrial sectors rose $17.2 \%$ and energy use rose 10\%. Between 2000 and 2010, CIPEC program continues to improve energy saving of Canadian's industrial sector. Some of this plan includes the following [36] [37] and [49]:

- Recognizing individual firms voluntary efforts to enhance their energy efficiency and minimize their environmental output.

- Organize the development of aggregated energy efficiency improvement commitments and sub-sector-level targets.

- encourage sub-sector-level implementation of action plans

- use sector task forces to encourage industries to exchange technical information and promote synergy among sectors

- encourage, facilitate, and provide energy management training.

\section{Practical Recommendations}

In order to reduce the dust control system airflow without affecting the ambient air quality in the workplace, here are some practical suggestions:

- Remove all duct leaks: Even with welded joints, a new duct system can leak up to $20 \%$ of the total system airflow. Sealing the leaks will allow the fan to slow down and the exhaust air to be reduced by the amount of duct leakage that has been eliminated. This has a direct effect on energy saving and to prevent a buildup.

- Install effective dust-capture hoods: Many dust control systems are missing capture hoods, because either they have been damaged and removed, or they 
were never designed and installed in the first place. Many plants use open-ended flexible ducts as dust capture devices. The amount of dust captured will be raised by up to 50 percent by installing properly designed dust-capture hoods.

- Operate exhaust fans efficiently: Use exhaust fans with low-energy motors. Variable-speed drives should be used if the fan load changes often. At each fan's inlet and exit, replace any restrictive ducting. Even though the fan is on the clean-air side of a dust collector, the fan blades must be inspected and cleaned on a regular basis.

- Check the dust collector filter cleaning timer: Continuously cleaning the filter media in the dust collector uses a lot of compressed air and may not be necessary. It may even shorten the filter media's useful life. It is recommended to use an on-demand timer that will effectively clean the filter media when the pressure drop across the media reaches a predetermined high point. The filters will be cleaned, the pressure drop across the media will fall, and the compressed air will be conserved.

Note that some suggestions here for reducing exhaust air and saving energy may require smaller ductwork to maintain minimum dust transport velocities within the ductwork. Before reducing the ductwork size, a study must be made to compare the cost of replacing ductwork to the dollar value of the contemplated changes in energy savings. Furthermore, a verification with the fan manufacturer would also be necessary to verify if slowing the fan for reduced airflow would still allow the fan to operate in the stable portion of the fan performance curve.

\section{Conclusions}

The excessive energy usage of most industrial manufacturers dust collection systems causes severe challenges. Though the concept for dust collection system seems simple, many things can go wrong if careful attentions are not brought to the design details. It has been found that energy saving technologies, for example use of HEM and VSD, to match load requirements have been found to be cost-effective energy saving measures to reduce energy consumption of major energy using equipment in the industrial facilities.

These savings strategies can be economically viable in most cases. It was also observed that effective public policies are also needed to reduce industrial energy consumption along with emission reduction.

In the end, it becomes desirable to reduce the airflow through the dust control system to the minimum required by the load on the system. So, the quantity and physical properties of the particles being extracted are the largest consumers of energy in the system.

\section{Conflicts of Interest}

The authors declare no conflicts of interest regarding the publication of this paper. 


\section{References}

[1] U.S Energy Information Administration (2020) International Energy Outlook 2020: World Energy and economic Outlook. http://www.eia.doe.gov/oiaf/ieo/world.html http://www.eia.doe.gov/oiaf/ieo/highlights.html http://www.eia.doe.gov/oiaf/ieo/industrial.html http://www.eia.doe.gov/emeu/aer/eh/total.html

[2] Kaplunov, D.R., Kalayeva, S.Z., Muratova, K.M. and Chistyakov, Ya.V. (2018) Analyzing Constructions of Dust Cyclone Types for Fine Dispersed Dust. Izvestiya Tul skogo gosudarstvennogo universiteta. Nauki o zemle, 2, 49-71.

[3] Azarov, V.N., Sergina, N.M., Ostaali, M., Sakharova, A.A. and Kopeikina, A.A. (2019) About Some Features of the Layout of Dust Cleaning Systems with Vortex Inertial Devices with Counter-Swirling Flow. Inzhenerniy vestnik Dona, 1. http://ivdon.ru/en/magazine/archive/n1y2019/5569

[4] Sergina, N.M. (2013) Vihrevye apparaty s zakruchennymi potokami s otsosom iz bunkera zoly v inertsionnyh sistemah pyleulavlivaniya. AP tenativnaya energetika $i$ ekologiya, 11, 43-46.

[5] Bulygin, Yu.I., Azimova, N.N. and Kuptsova, I.S. (2018) Problems of Designing Dust Cleaning Equipment in the Industry. Bezopasnost' tehnogennyh i prirodnyh sistem, 1-2, 2-12.

[6] Muratova, K.M., Makhnin, A.A., Volodin, N.I. and Chistyakov, Y.V. (2017) Treatment of Industrial Dust-Air Flows in CentrifugalInertial Apparatuses. Chemical and Petroleum Engineering, 53, 185-189. https://doi.org/10.1007/s10556-017-0319-5

[7] Hsiao, T.-C., Chen, D., Greenberg, P.S. and Street, K.W. (2011) Effect of Geometric Configuration on the Collection Efficiency of Axial Flow Cyclones. Journal of Aerosol Science, 42, 78-86. https://doi.org/10.1016/j.jaerosci.2010.11.004

[8] Park, C.-W., Song, D.-H. and Yook, S.-J. (2015) Development of a Single Cyclone Separator with Three Stages for Size-Selective Sampling of Particles. Journal of Aerosol Science, 89, 18-25. https://doi.org/10.1016/j.jaerosci.2015.07.001

[9] Baltrenas, P., Pranskevicius, M. and Venslovas, A. (2015) Optimization of the New Generation Multichannel Cyclone Cleaning Efficiency. Energy Procedia, 72, 188-195. https://doi.org/10.1016/j.egypro.2015.06.027

[10] Balestrin, E., Decker, R.K., Noriler, D., Bastos, J.C.S.C. and Meier, H.F. (2017) An Alternative for the Collection of Small Particles in Cyclones: Experimental Analysis and CFD Modeling. Separation and Purification Technology, 184, 54-65. https://doi.org/10.1016/j.seppur.2017.04.023

[11] Chlebnikovas, A. and Baltrenas, P. (2017) Research and Analysis of Aggressive Conditions Formation into a Multi Channel Cyclone. Energy Procedia, 113, 69-76. https://doi.org/10.1016/j.egypro.2017.04.018

[12] Shcherbyna, V.Yu. (2019) Modeling the Process of Separation in Cyclonic Wiring Apparatus. Proceedings of the NTUU "Igor Sikorsky KPI". Series: Chemical Engineering, Ecology and Resource Saving, 1, 40-51. https://doi.org/10.20535/2617-9741.1.2019.171037

[13] Petrecca, G. (1992) Industrial Energy Management: Principles and Applications. Kluwer Academic Publisher, Dordrecht. https://doi.org/10.1007/978-1-4615-3160-9

[14] Bureau of Energy Efficiency (2010) Energy Management and Audit. http://www.em-ea.org/Guide\%20Books/book-2/2.8\%20Waste\%20Heat\%20Recover y.pdf

[15] Kannan, R. and Boie, W. (2003) Energy Management Practices in SME-Case Study 
of a Bakery in Germany. Energy Conversion and Management, 44, 945-959. https://doi.org/10.1016/S0196-8904(02)00079-1

[16] AST Canada. Best Practices in Dust Collector Hood Design. HoodDesign_Hildebrand.pdf (astcanada.ca)

[17] ACGIH Ventilation. Industrial Ventilation: A Manual of Recommended Practice for Design, 30th Edition. Store-Industrial Ventilation: A Manual of Recommended Practice for Design, 30th Edition-ACGIH Portal.

[18] Hammertek Corporation: Smart Elbow-Deflection Elbows for Pneumatic Conveying Systems. https://www.hammertek.com

[19] Wang, P.F., Gao, R.Z., Liu, R.H. and Yang, F.Q. (2020) CFD-Based Optimization of the Installation Location of the Wall-Mounted Air Duct in a Fully Mechanized Excavation Face. Process Safety and Environmental Protection, 141, 234-245. https://doi.org/10.1016/j.psep.2020.04.049

[20] Mecrow, B.C. and Jack, A.G. (2008) Efficiency Trends in Electric Machines and Drives. Energy Policy, 36, 4336-4434. https://doi.org/10.1016/j.enpol.2008.09.042

[21] Saidur, R. (2009) Energy Consumption, Energy Savings, and Emission Analysis in Malaysian Office Buildings. Energy Policy, 37, 4104-4113. https://doi.org/10.1016/j.enpol.2009.04.052

[22] Tolvanen, J. (2008) Saving Energy with Variable Speed Drives. World Pumps, 501, 32-33. https://doi.org/10.1016/S0262-1762(08)70164-0

[23] Saidur, R., Rahim, N.A., Ping, H.W., Jahirul, M.I., Mekhilef, S. and Masjuki, H.H. (2009) Energy and Emission Analysis for Industrial Motors in Malaysia. Energy Policy, 37, 3650-3658. https://doi.org/10.1016/j.enpol.2009.04.033

[24] Saidur, R. (2009) A Review on Electrical Motors Energy Use and Energy Savings. Renewable and Sustainable Energy Reviews, 14, 877-898. https://doi.org/10.1016/j.rser.2009.10.018

[25] Tripathy, S.C. (1994) Energy Conservation with Efficient Electric Drives. Energy Conversion, 36, 125-123. https://doi.org/10.1016/0196-8904(94)00029-Y

[26] Saidur, R. and Mahlia, T.M.I. (2010) Energy, Economic and Environmental Benefits of Using High-Efficiency Motors to Replace Standard Motors for the Malaysian Industries. Energy Policy, 38, 4617-4612. https://doi.org/10.1016/j.enpol.2010.04.017

[27] Saidur, R., Rahim, N.A., Masjuki, H.H., Mekhilef, S., Ping, H.W. and Jamaluddin, M.F. (2009) Enduse Energy Analysis in the Malaysian Industrial Sector. Energy, 34, 153-158. https://doi.org/10.1016/j.energy.2008.11.004

[28] Constance, J.A. (2004) Energy-Saving Tips for Your Dust Control System. Powder and Bulk Engineering, 18, 40-44.

[29] Traub, D.A. (2000) How to Prevent Dust Leaks in a Reverse Pulsing Dust Collector. Powder and Bulk Engineering, 14, 59-65.

[30] Maynard, E. (2018) Six Key Considerations for Proper Dust Collection System Design. https://www.powderbulk.com/wp-content/uploads/pdf/pbe 20181001 0022.pdf

[31] Jacobs, N.B. (2009) Energy Policy: Economic Effects, Security Aspects and Environmental Issues. Nova Science Publishers Inc., Hauppauge.

[32] Price, L. and Worrell, E. (2000) International Industrial Sector Energy Efficiency Policies. Lawrence Berkeley National Laboratory [LBNL-46274]. https://doi.org/10.2172/810469

[33] Bertoldi, P. (1999) The Use of Long-Term Agreements to Improve Energy Efficien- 
cy in the Industrial Sector: Overview of the European Experiences and Proposal for a Common Framework. In: Proceedings of the 1999 American Council for an Energy-Efficient Economy Summer Study on Energy Efficiency in Industry, ACEEE, Washington DC, 287-297.

[34] Chidiak, M. (1999) Voluntary Agreements for Energy Efficiency in Five EU Countries. In: Bin Energy Efficiency and $\mathrm{CO}_{2}$ Reduction: The Dimensions of Social Change: 1999 European Council for an Energy-Efficient Economy Summer Study, CERNA, Paris.

[35] Newman, J. (1998) Evaluation of Energy-Related Voluntary Agreements. Industrial Energy Efficiency Policies. Understanding Success and Failure. Proceedings of a Workshop Organized by the International Network for Energy Demand Analysis in the Industrial Sector, Utrecht, The Netherlands, LBNL-42368.

[36] McKenzie, R. (1994) Canada's National Partnership Strategy for Industrial Energy Efficiency. International Energy Agency, Conference Proceedings-Industrial Energy Efficiency. Policies and Programs, Washington DC, 26-27.

[37] Jago, P. (1999) The Canadian Industry Program for Energy Conservation (CIPEC): The Dynamics of a 24-Year Partnership between Government and Industry. In: Proceedings of the 1999 American Council for an Energy-Efficient Economy Summer Study on Energy Efficiency in Industry, ACEEE, Washington DC.

https://www.osti.gov/biblio/20001853

[38] Togeby, M., Bjorner, T.B. and Johannsen, K. (1998) Evaluation of the Danish $\mathrm{CO}_{2}$ Taxes and Agreements. Industrial Energy Efficiency Policies: Understanding Success and Failure: Proceedings of a Workshop Organized by the International Network for Energy Demand Analysis in the Industrial Sector.

[39] Kraemer, T.P. and Lajla, S. (1996) Energy Policy Instruments: Description of Selected Countries. Institute of Local Government Studies, Copenhagen.

[40] Krarup, S. and Ramesohl, S. (2002) Voluntary Agreements on Energy Efficiency in Industry-Not a Golden Key, But Another Contribution to Improve Climate Policy Mixes. Journal of Cleaner Production, 10, 109-120. https://doi.org/10.1016/S0959-6526(01)00032-4

[41] Ramesohl, S. and Kristof, K. (1999) What Is the Role of Energy-Related Voluntary Approaches in the Post-Kyoto Climate Policy? A Process Oriented Analysis of the Declaration of German Industry on Global Warming Prevention. Energy Efficiency and $\mathrm{CO}_{2}$ Reduction: The Dimensions of Social Change: 1999 European Council for an Energy-Efficient Economy Summer Study, Wuppertal, 1-13.

http://citeseerx.ist.psu.edu/viewdoc/download?doi=10.1.1.198.2090\&rep=rep1\&type $=\mathrm{pdf}$

[42] Korevaar, E., Farla, J., Blok, K. and Schulte Fischedick, K. (1997) A Preliminary Analysis of the Dutch Voluntary Agreements on Energy Efficiency Improvement. The Energy Efficiency Challenge, Proceedings 1997 ECEEE Summer Study, Copenhagen, ID52.1-ID52.15.

[43] Miles, J. (1994) The UK Energy Efficiency Best Practice Program. International Energy Agency, Conference Proceedings-Industrial Energy Efficiency: Policies and Programs, Washington DC, 26-27 May 1994, 26-27.

[44] ETSU-AEA Technology (2000) Climate Change Agreements-Sectoral Energy Efficiency Targets. Version 2. ETSU-AEA Technology, Oxfordshire.

[45] Chidiak, M. (2000) Voluntary Agreements-Implementation and Efficiency. The French Country Study: Case Studies in the Sectors of Packaging, Glass, and Aluminum. CERNA, Paris. 
[46] Uggla, U. and Avasoo, D. (2001) EKO-Energy—Successful Voluntary Agreements on Energy Efficiency and Environmental Control in Swedish Industry. Proceedings of the 2001 ECEEE Summer Study. European Council for an Energy-Efficient Economy, Stockholm, 5574-5583.

[47] Finden, P. (1998) Norwegian Industry's Network for Energy Conservation. Industrial Energy Efficiency Policies: Understanding Success and Failure: Proceedings of a Workshop Organized by the International Network for Energy Demand Analysis in the Industrial Sector, Utrecht.

[48] Eichhorst, U. and Bongardt, D. (2009) Towards Cooperative Policy Approaches in China-Drivers for Voluntary Agreements on Industrial Energy Efficiency in Nanjing. Energy Policy, 37, 1855-1865. https://doi.org/10.1016/j.enpol.2009.01.024

[49] CIPEC Annual Report (2016) From Actions to Winning Results-CIPEC Annual Report 2016 (nrcan.gc.ca). 